\title{
AVALIAÇÃo histopatológiCA, hISTOENZIMOLóGiCA, IMUNOHISTOQUÍMICA E POR IMUNOFLUORESCÊNCIA DA RESPOSTA TECIDUAL FRENTE A MATERIAIS SELADORES, APÓS PERFURAÇÃO DE FURCA
}

\author{
Tese de Doutorado apresentada à Faculdade de \\ Odontologia de Ribeirão Preto da Universidade de São \\ Paulo para a obtenção do título de Doutor em Ciências. \\ Programa: Odontopediatria. \\ Área de Concentração: Odontopediatria.
}

Orientadora: Profa. Dra. LÉa Assed BeZerRa da Silva 


\section{AUtORIZAÇÃo PARA RePROdUÇÃo}

Autorizo a reprodução e divulgação total ou parcial deste trabalho, por qualquer meio convencional ou eletrônico para fins de estudo e pesquisa, desde que citada a fonte.

\section{Alberto TADeU do NAscimento Borges}

\section{Ficha CATALOgRÁfica}

Borges, Alberto Tadeu do Nascimento

Avaliação histopatológica, histoenzimológica, imunohistoquímica e por imunofluorescência da resposta tecidual frente a materiais seladores, após perfuração de furca. Ribeirão Preto, 2018.

74p. : il. ; $30 \mathrm{~cm}$

Tese de Doutorado apresentada à Faculdade de Odontologia de Ribeirão Preto da Universidade de São Paulo (FORP-USP) - Área de concentração: Odontopediatria.

Orientadora: Profa. Dra. Léa Assed Bezerra da Silva

1. Biodentine 2. MTA 3. Perfuração de furca 4. Histopatologia 5. Imunohistoquímica 6 . Imunofluorescência. 
Borges ATN. Avaliação histopatológica, histoenzimológica, imunohistoquímica e por imunofluorescência da resposta tecidual frente a materiais seladores, após perfuração de furca.

Tese de Doutorado apresentada à Faculdade de Odontologia de Ribeirão Preto da Universidade de São Paulo para a obtenção do título de Doutor em Ciências Programa: Odontopediatria.

Área de Concentração: Odontopediatria.

Data da defesa:

BANCA EXAMINADORA

$\operatorname{Prof}(a) \cdot \operatorname{Dr}(a)$ :

Julgamento: Assinatura:

$\operatorname{Prof}(a) \cdot \operatorname{Dr}(a)$ :

Julgamento: Assinatura:

$\operatorname{Prof}(a) \cdot \operatorname{Dr}(a)$ :

Julgamento: Assinatura:

Profa. Dra. Léa Assed Bezerra da Silva - Orientadora e Presidente da Banca Examinadora

Assinatura: 



\title{
ALBERTO TADEU DO NASCIMENTO BORGES
}

\author{
DAdos CurRiculares
}

1977 - 1981 Curso de Graduação em Odontologia.

Universidade Federal do Amazonas, UFAM, Brasil.

1981 - 1983 Especialização em Cirurgia e Traumatologia Buco-Maxilo-Facial.

Universidade Federal do Ceará, UFC, Brasil.

Título: Sequelas de fraturas condilianas.

1986 - 1986 Especialização em Administração dos Serviços de Saúde.

Universidade de Ribeirão Preto, UNAERP, Brasil.

1995 - 1997 Especialização em Implantodontia.

Universidade Federal do Ceará, UFC, Brasil.

Título: Enxerto de osso autógeno na região anterior da maxila.

2003 - 2005 Curso de Pós-Graduação em Odontopediatria, nível Mestrado.

Faculdade de Odontologia de Ribeirão Preto

Universidade de São Paulo, USP, Brasil.

Título: Avaliação radiográfica da reabsorção óssea peri-implantar após implante em dentes de cães.

Orientador: Prof. Dr. Mário Roberto Leonardo. 

DEDICATÓRIA

Aos meus pais (In memoriam) Alberto e Nice a quem devo a minha vida.

À minha esposa Zobélia e ao meu filho Luã, porque sem eles a minha vida não teria sentido. 

AGradeCIMENTO ESPECIAL

Gostaria aqui de expressar os meus mais sinceros agradecimentos à minha orientadora Profa. Dra. Léa Assed Bezerra da Silva que por meio de seu dinamismo, suas convicções e do seu ideal como verdadeira professora e formadora de pensadores contribuiu magnificamente com a minha formação e meu crescimento profissional. 

À Universidade de São Paulo, na pessoa do atual Reitor, Prof. Dr. Vahan Agopyan, e do Vice-reitor, Prof. Dr. Antonio Carlos Hernandes.

À Faculdade de Odontologia de Ribeirão Preto da Universidade de São Paulo, na pessoa da Diretora, Profa. Dra. Léa Assed Bezerra da Silva, e do Vice-Diretor, Prof. Dr. Arthur Belém Novaes Jūnior.

À Coordenação do curso de Pós-Graduação em Odontopediatria da Faculdade de Odontologia de Ribeirão Preto da Universidade de São Paulo, na pessoa da Coordenadora, Profa. Dra. Raquel Assed Bezerra Segato, e da Vice-Coordenadora, Profa. Dra. Léa Assed Bezerra da Silva.

Aos Professores do Departamento de Clínica Infantil da FORP/USP, Profa. Dra. Aldevina Campos de Freitas, Profa. Dra. Alexandra Mussolino de Queiroz, Profa. Dra. Andiara De Rossi Daldegan, Prof. Dr. Fabio Lourenço Romano, Prof. Dr. Fabrício Kitazono de Carvalho, Profa. Dra. Kranya Victoria Díaz Serrano, Profa. Dra. Léa Assed Bezerra da Silva, Profa. Dra. Maria Bernadete Sasso Stuani, Profa. Dra. Maria Cristina Borsato, Profa. Dra. Maria da Conceição Pereira Saraiva, Profa. Dra. Mirian Aiko Nakane Matsumoto, Prof. Dr. Paulo Nelson Filho, Profa. Dra. Raquel Assed Bezerra Segato e Prof. Dr. José Tarcísio Lima Ferreira.

Ao Prof. Dr. Alberto Consolaro, docente do Programa de Pós-Graduação em Odontopediatria da FORP/USP.

Às alunas do Programa de Pós-Graduação em Odontopediatria da FORP/USP, Carolina Maschietto Pucinelli e Priscilla Coutinho Romualdo.

Aos funcionários do Departamento da Clínica Infantil, Carmo Eurípedes Terra Barreto (in Memoriam), Dra. Carolina Paes Torres Mantovani, Fátima Aparecida Jacinto Daniel, Fátima Rizoli, Filomena Leli Placciti, Dr. Francisco Wanderley Garcia de Paula e Silva, Marco Antônio dos Santos, Dra. Marilia Pacífico Lucisano, Matheus Morelli Zanela, Micheli Cristina Leite Rovanholo e Nilza Letícia Magalhães. 

SuMÁRIO

RESUMO

ABSTRACT

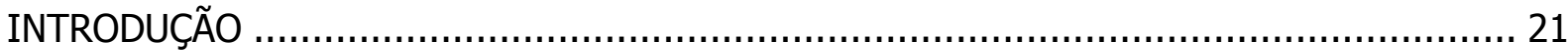

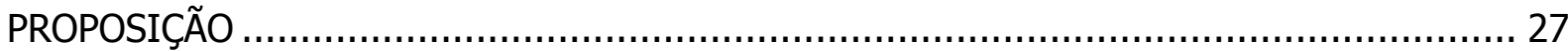

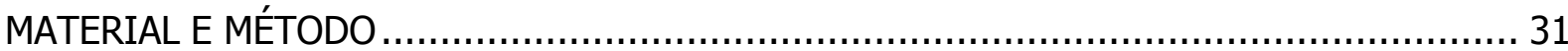

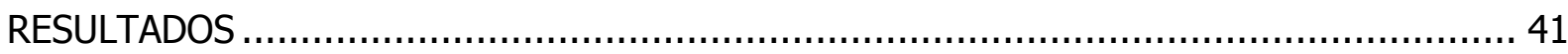

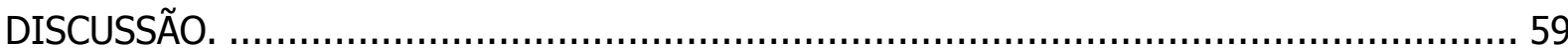

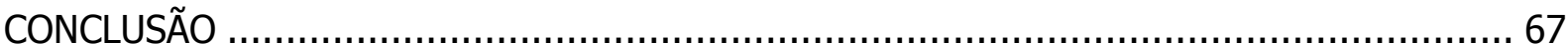

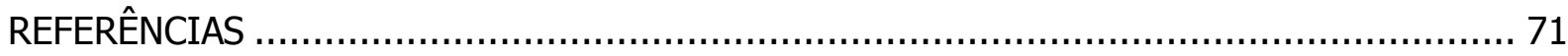





\section{RESUMO}

Borges, ATN. Avaliação histopatológica, histoenzimológica, imunohistoquímica e por imunofluorescência da resposta tecidual frente a materiais seladores, após perfuração de furca. Ribeirão Preto, 2018. 74p. Tese [doutorado]. Faculdade de Odontologia de Ribeirão Preto, Universidade de São Paulo.

Objetivo: Avaliar in vivo a resposta tecidual de dentes de cães após perfuração de furca e recobrimento com Biodentine ${ }^{\mathrm{TM}}$, em comparação ao MTA e à guta-percha, por meio de análise histopatológica, histoenzimológica, imunohistoquímica e por imunofluorescência. Métodos: Foram utilizados 30 dentes de 3 cães, divididos em 3 grupos: I - Biodentine; II MTA; e III - Guta-Percha (controle). Após tratamento endodôntico e limpeza da câmara pulpar, perfurações no centro do assoalho foram realizadas intencionalmente em cada dente, as quais foram preenchidas com os diferentes materiais. Após 120 dias, os animais foram eutanasiados e as peças contendo os dentes e tecidos perirradiculares foram submetidas ao processamento histotécnico. Foram realizadas análises histopatológicas semi-quantitativas para avaliação da neoformação de tecido mineralizado e da reinserção de fibras, além de análise imunohistoquímica das proteínas osteopontina (OPN) e fosfatase alcalina (ALP) e imunofluorescência para proteína morfogenética óssea (BMP-2), proteína de adesão do cemento (CAP), sialoproteína óssea (BSP), osteocalcina (OCN) e proteína do cemento 1 (CEMP1) no tecido mineralizado neoformado e na região adjacente. Paralelamente, foi realizada a histoenzimologia para a atividade da TRAP e contagem dos osteoclastos. Os dados foram submetidos aos testes qui-quadrado e Kruskal-Wallis, com nível de significância de 5\%. Resultados: Na avaliação do tecido mineralizado neoformado, o grupo controle foi significantemente diferente dos demais grupos $(p<0,0001)$, sendo que não houve formação de tecido mineralizado em nenhum espécime desse grupo. Nos grupos tratados com MTA e Biodentine houve formação de tecido mineralizado em $88 \%$ e $92 \%$ dos espécimes, respectivamente, sem diferença entre eles $(p>0,05)$. Ainda, o grupo controle apresentou fibras colágenas paralelas à perfuração. Nos grupos tratados com MTA ou Biodentine também houve fibras colágenas paralelas à perfuração, porém com algumas fibras reinseridas perpendicularmente em diferentes áreas do tecido mineralizado neoformado. Todos os tratamentos induziram a expressão de OPN e ALP, porém em menor intensidade no grupo controle e em maior intensidade no grupo tratado com MTA $(p<0,05)$. Apenas o tecido mineralizado formado após o tratamento com MTA expressou BMP-2, BSP, OCN, CAP e CEMP1. Com relação à avaliação dos osteoclastos, não foi possível encontrar diferença estatística entre os grupos $(p=0,97)$. Conclusão: Com base nos parâmetros analisados, pôde-se concluir que o MTA e a Biodentine apresentaram resposta tecidual satisfatória, com formação de tecido mineralizado e reinserção parcial de fibras, podendo ser indicados para o selamento de perfurações de furca. Além disso, o presente estudo elucidou alguns mecanismos de ação pelo quais o MTA e a Biodentine induzem a formação do tecido mineralizado, com expressão dos marcadores da mineralização ALP e OPN, sem interferência na quantidade de osteoclastos. Apenas o MTA estimulou a expressão de proteínas associadas à formação de tecido mineralizado semelhante ao cemento.

Palavras-chave: Biodentine. MTA. Perfuração de furca. Histopatologia. Imunohistoquímica. Imunofluorescência. 

Borges, ATN. Histopathological, histoenzymological, immunohistochemical and immunofluorescence analysis of tissue response to sealing materials after furcation perforation. Ribeirão Preto, 2018. 74p. Tese [doutorado]. Faculdade de Odontologia de Ribeirão Preto, Universidade de São Paulo.

Aim: This study evaluated in vivo tissue response in dog's teeth after sealing of furcation perforations with Biodentine ${ }^{\mathrm{TM}}$, MTA and gutta-percha, by means of histopathological, histoenzymological, immunohistochemical and immunofluorescence analysis. Methods: Thirty teeth of 3 dogs were used, divided in 3 groups: I - Biodentine; II - MTA; and III Guta-Percha (control). After endodontic treatment, perforations were made on the pulp chamber floor and filled with the different materials. The animals were euthanized after 120 days and the teeth and surrounding tissues were processed for histopathological analysis of new mineralized tissue formation and collagen fiber reinsertion, immunohistochemical analysis of osteopontin (OPN) and alkaline phosphatase (ALP) and immunofluorescence analysis for bone morphogenetic protein (BMP-2), cementum attachment protein (CAP), bone sialoprotein (BSP), osteocalcin (OCN) and cementum protein1 (CEMP1). Histoenzymology was performed for TRAP activity and osteoclast count. Data were submitted to chi-square and Kruskal-Wallis tests $(a=0.05)$. Results: Gutta-percha did not induce mineralized tissue formation. MTA and Biodentine formed mineralized tissue in $88 \%$ and $92 \%$ of specimens, respectively, with no significant difference $(p>0.05)$. In addition, the control group had collagen fibers parallel to the perforation. In the groups treated with MTA or Biodentine there were also collagen fibers parallel to the perforation, but with some fibers reinserted perpendicularly in different areas of the neoformed mineralized tissue. All materials induced OPN and ALP expression, weakest for gutta-percha and strongest for MTA $(p<0.05)$. Only MTA induced BMP-2, BSP, OCN, CAP and CEMP1 expression. Osteoclast count was similar in the groups $(p=0.97)$. Conclusion: Thus, according to the parameters analyzed in this present study, MTA and Biodentine presented satisfactory tissue response, with formation of mineralized tissue and partial reinsertion of fibers, and could be indicated for sealing furcation perforations. In addition, the present study elucidated some mechanisms of action by which MTA and Biodentine induce the formation of mineralized tissue, with expression of ALP and OPN mineralization markers, without interference in number of osteoclasts. Only MTA stimulated the expression of proteins associated with the formation of a cement-like mineralized tissue.

Key words: Biodentine. MTA. Furcation perforation. Histopathology. Immunohistochemistry. Immunofluorescence. 

Introdução 



\section{INTRODUÇÃO}

A perfuração de furca é definida como uma comunicação patológica ou iatrogênica entre o espaço do canal radicular e os tecidos perirradiculares. Eventos patológicos como lesões de cáries e reabsorções dentárias ou a ocorrência de perfuração iatrogênica durante procedimentos restauradores ou endodônticos são as causas principais das perfurações de furca (American Association of Endodontists, 2015; Katge et al., 2016; Cardoso et al., 2017), que podem afetar o sucesso do tratamento endodôntico (Bakhtiar et al., 2017).

Independentemente da etiologia, a perfuração de furca é considerada uma complicação clínica, pois desencadeia uma reação inflamatória no periodonto que pode levar à destruição do ligamento periodontal, com perda dos tecidos de suporte. Na prática clínica, a perfuração de furca é considerada uma condição grave, sendo a segunda causa mais frequente de falhas no tratamento endodôntico, seguida pela obturação (Singh et al., 2013). Portanto, o reparo da perfuração com material biocompatível apresenta grande importância clínica na prevenção das consequências inflamatórias no periodonto e na prevenção da perda dentária (Cardoso et al., 2017).

Avanços recentes na Endodontia e no estudo dos biomateriais têm focado na manutenção dos dentes afetados, mesmo nos casos mais complicados. Assim, diversos materiais promissores surgiram nos últimos anos visando o reparo das perfurações de furca (Cardoso et al., 2017). Com essa finalidade, um material ideal deve fornecer selamento adequado, ser biocompatível, não ser afetado pela contaminação sanguínea, ser radiopaco, induzir a mineralização e ser de fácil manipulação e inserção (Aggarwal et al., 2013).

O agregado de trióxido mineral (MTA) é um cimento de silicato tricálcico que tem sido considerado o material de escolha para o reparo de perfurações de furca, sendo considerado o padrão-ouro em pesquisas na área (Parirokh e Torabinejad, 2010; Silva et al., 2017). Este material apresenta excelente biocompatibilidade e capacidade de selamento, e está associado a resultados clínicos favoráveis quando usado no reparo de perfurações, nas terapias de dentes com vitalidade pulpar, em obturações radiculares e como tampão apical (Torabinejad e Parirokh, 2010). 
Apesar das inúmeras propriedades favoráveis do MTA que justificam o seu uso, esse material apresenta algumas desvantagens clínicas, como o tempo prolongado de presa que pode levar à microinfiltração, manipulação difícil e potencial alteração de cor do elemento dental (Unal et al., 2010; Flores-Ledesma et al., 2017). Além disso, em contato com o fluido tecidual, o MTA libera alguns componentes químicos, incluindo íons cálcio e sílica (Camilleri, 2008), podendo afetar a atividade biológica das células dos tecidos perirradiculares, responsáveis pelo processo de reparo do tecido periapical (Cheng et al., 2017). Assim, na tentativa de superar as desvantagens do MTA, novos cimentos endodônticos bioativos à base de silicato de cálcio foram recentemente introduzidos no mercado. Os cimentos de silicato tricálcico são indicados para diferentes aplicações clínicas, tais como proteção pulpar direta, pulpotomia, reparo de reabsorções dentárias, reparo de perfuração radicular e de furca, dentre outras (Rathinam et al., 2016).

A Biodentine $^{\mathrm{TM}}$, introduzida por Gilles e Olivier em 2011, é um cimento endodôntico bioativo à base de silicato de cálcio, sob a forma de pó de silicato tricálcico, silicato dicálcico, carbonato de cálcio e óxido de zircônio $\left(\mathrm{ZrO}_{2}\right)$ e líquido à base de água contendo cloreto de cálcio $(\mathrm{CaCl})$ como acelerador. Assim como o MTA, a Biodentine demonstrou liberar hidróxido de cálcio, induzir a síntese reparadora da dentina e ter atividade antibacteriana (Laurent et al., 2012; Camilleri, 2013). É um material indicado como substituto dentinário e pode ser usado como material de reparo de perfurações endodônticas, devido à sua adequada capacidade de vedamento, alta resistência à compressão, tempo de presa curto, biocompatibilidade e propriedades biomineralizadoras (Leiendecker et al., 2012). Embora a Biodentine seja à base de silicato tricálcico, assim como o MTA, a ausência do aluminato possibilita um tempo de trabalho reduzido e evita potenciais riscos à saúde (Camilleri, 2013). Além disso, a Biodentine possui baixa citotoxicidade (Zhou et al., 2013) e promove pouca alteração de cor (Marconyak et al., 2016). De acordo com uma revisão sistemática recente (Możyńska et al., 2017), a Biodentine está entre os materiais capeadores que menos alteram a coloração dentária, sendo esta quase invisível ao olho humano.

Estudo prévio realizado por nosso grupo de pesquisa demonstrou que a Biodentine apresenta compatibilidade tecidual e permite a formação de ponte de 
tecido mineralizado semelhante, porém com maior espessura, em comparação ao MTA, após pulpotomias em dentes de cães (De Rossi et al., 2014). Ainda, ambos os materiais foram capazes de induzir a expressão de marcadores da mineralização, quando em contato com células pulpares, in vitro e in vivo (Daltoe et al., 2016). Entretanto, Torabinejad et al. (2018), em revisão recente da literatura, concluíram que o número de pesquisas avaliando os cimentos endodônticos bioativos nas diversas aplicações clínicas ainda é limitado, e que a maioria dos estudos existentes apresenta várias deficiências metodológicas e baixos níveis de evidência.

Portanto, ainda não é bem estabelecido na literatura específica qual seria a melhor abordagem nos casos de perfuração de furca, fazendo-se necessário o desenvolvimento de estudos in vivo que simulem as características clínicas desta patologia. Em 2017, Cardoso et al. realizaram uma revisão sistemática que demonstrou a importância do modelo experimental escolhido para esse tipo de estudo, o qual deveria simular a condição clínica humana. Embora não haja um modelo sem desvantagens que possa ser estabelecido como ideal, os autores indicaram que os estudos em dentes de cães parecem apresentar as características de um modelo adequado.

$\mathrm{Na}$ literatura específica, apenas um estudo avaliou o efeito biológico da Biodentine no reparo de perfurações de furca, in vivo (Silva et al., 2017), demonstrando que este material e o MTA apresentam bons resultados histopatológicos em dentes de cães, sendo considerados materiais adequados para o reparo de perfuração de furca. Entretanto, estudos adicionais in vivo são necessários para avaliar a resposta tecidual perirradicular e elucidar particularidades do mecanismo de ação que provoca a mineralização, após o uso desses materiais. 

Proposição 



\section{Proposição}

O objetivo do presente estudo foi avaliar in vivo a resposta tecidual de dentes de cães após perfuração de furca e recobrimento com Biodentine ${ }^{\mathrm{TM}}$, em comparação ao MTA e à guta-percha, por meio de análise histopatológica, histoenzimológica, imunohistoquímica e por imunofluorescência. 

Material e Métodos 



\section{Material e Métodos}

O presente estudo foi submetido à apreciação pela Comissão de Ética em Experimentação Animal (CEUA) da Faculdade de Odontologia de Ribeirão Preto da Universidade de São Paulo (FORP/USP), tendo sido aprovado (processo $\mathrm{n}^{0}$ 2014.1.76.58.4). Todos os procedimentos seguiram as Normas e Princípios Éticos adotados pela CEUA e as Resoluções Normativas do Conselho Nacional de Controle de Experimentação Animal (CONCEA).

\section{Procedimentos operatórios}

Foram utilizados os $2^{\text {os }}$ e $3^{\text {os }}$ pré-molares superiores e os $2^{\text {os }}, 3^{\text {os }}$ e $4^{\text {os }}$ prémolares inferiores permanentes de 3 cães da raça Beagle, com 12 meses de idade. Durante todo o experimento, os animais foram mantidos no Biotério II da FORP/USP, alojados em baias individuais, com livre acesso à água e ração, sob o supervisionamento diário de um veterinário experiente. Previamente ao início do experimento, todos os animais foram devidamente vacinados.

Foram utilizados 30 dentes, divididos em 3 grupos: I - Biodentine ${ }^{\mathrm{TM}}$ (Septodont, St-Maur-des-Fossés, França); II - Agregado de Trióxido Mineral branco (ProRoot ${ }^{\circledR}$ White MTA, Dentsply Tulsa Dental Specialties, Tulsa, OK, EUA); e III Guta-Percha (controle) em bastão (Odahcan Maillefer, Dentsply, Teresópolis, RJ, Brasil). A composição dos materiais experimentais utilizados está listada na Tabela 1. Para que todas as variáveis fossem testadas em um mesmo animal, em diferentes quadrantes, cada hemiarco recebeu um material em sistema de rodízio, distribuído ao acaso.

Os animais foram pré-anestesiados por meio de injeção intramuscular de acepromazina (Acepran 0,2\% - Univet SA, São Paulo, SP, Brasil), 0,05 mg/kg de peso, 15 minutos antes do procedimento operatório. Decorrido esse tempo, foi aplicado zolazepam (Zoletil ${ }^{\circledR}$ 50, Virbac do Brasil, São Paulo, SP, Brasil), $10 \mathrm{mg} / \mathrm{kg}$ de peso, via endovenosa. A manutenção da anestesia foi realizada por meio de anestesia inalatória com isoflurano (Baxter Hospitalar Ltda, São Paulo, SP, Brasil), na 
concentração de 1,5 a 2,5\%, juntamente com oxigênio, utilizando o aparelho para anestesia inalatória (Takaoka KT-20, Biocom Tecnologia, São Paulo, SP, Brasil). Durante todo $\circ$ procedimento operatório, os animais permaneceram sob monitoramento cardiorrespiratório realizado com o auxílio de um oxímetro de pulso veterinário (Edan ZEH100B, Sistem Biomédica, Yucatan, México).

Foi realizado exame radiográfico periapical de todos os dentes, com filmes periapicais n02 ultrarrápidos (Eastman Kodak Company, Rochester, NY, EUA), pela técnica da bissetriz, para confirmação do completo desenvolvimento radicular e ausência de quaisquer alterações. Após profilaxia, procedeu-se ao isolamento do campo operatório com dique de borracha, seguido de antissepsia com gluconato de clorexidina a $2 \%$. Para a abertura coronária foram utilizadas pontas esféricas diamantadas no1012 (K.G. Sorensen, São Paulo, SP, Brasil) em alta rotação e sob refrigeração ar/água. A cada 3 aberturas uma nova ponta foi utilizada para assegurar a eficiência do corte e evitar aquecimento.

Após a abertura coronária, foi realizada a pulpectomia com lima tipo Hedstroen (Dentsply/Maillefer, Oklahoma, EUA). A determinação do comprimento de trabalho ( $2 \mathrm{~mm}$ aquém do ápice radicular) foi realizada por meio de um localizador eletrônico foraminal (Root ZXII, J Morita Corp., Kyoto, Japão). Em seguida, foi realizada a instrumentação dos canais radiculares com limas de níquel-titânio do Sistema Protaper Universal (Dentsply/Maillefer, Oklahoma, EUA), acionadas pelo motor X-Smart (Dentsply/Maillefer), sob irrigação com hipoclorito de sódio a 1\% (3,6 $\mathrm{mL}$ a cada troca de instrumento). Os canais radiculares foram secos utilizando-se pontas de papel absorvente esterilizadas, seguido da obturação dos canais com cones de guta-percha e cimento AH Plus (Dentsply, De Trey, Konstanz, Alemanha), por meio da técnica de condensação lateral.

Após limpeza da câmara pulpar, uma perfuração foi realizada intencionalmente no centro do assoalho da câmara pulpar com ponta esférica diamantada 1012 (KG Sorensen, São Paulo, SP, Brasil), cujo diâmetro foi o tamanho padrão para as perfurações de todos os grupos. O sangramento foi controlado por meio de irrigação com soro fisiológico e secagem com mechas de algodão esterilizado. A cada 3 perfurações foi utilizada uma nova ponta. 
As perfurações foram então preenchidas com os diferentes materiais. A Biodentine e o MTA foram manipulados de acordo com as instruções dos fabricantes e aplicados sobre a lesão de furca, até o seu completo preenchimento. Ambos os materiais foram aplicados com o auxílio de uma cureta, sem pressão excessiva, aguardando o tempo de presa de 12 minutos. Nos dentes do grupo controle, as perfurações de furca foram preenchidas com guta-percha em forma de bastão (Odahcan Maillefer, Dentsply, Teresópolis, RJ, Brasil), levemente aquecida. Em todos os grupos, as aberturas coronárias foram restauradas com amálgama de prata (Sybraloy, Kerr Corporation, Orange, CA, EUA). Então, foi realizada uma segunda radiografia periapical de cada dente, conforme descrito anteriormente. Todos os procedimentos foram realizados por um único operador experiente.

Os animais foram acompanhados no período pós-operatório até a completa recuperação anestésica. Além disso, foi administrado um fármaco analgésico (Tramal 50 mg/mL, União Química Farmacêutica Nacional, Pouso Alegre, MG, Brasil), 3 $\mathrm{mg} / \mathrm{kg}$, via subcutânea, de 8/8 horas, durante 3 dias.

Após 120 dias, os animais foram eutanasiados de acordo com as diretrizes da prática de eutanásia do CONCEA.

Tabela 1. Composição dos materiais experimentais utilizados

Material

Composição

\begin{tabular}{|c|c|}
\hline Biodentine $^{\mathrm{TM}}$ & $\begin{array}{l}\text { Pó: Silicato tricálcico; Silicato dicálcico; Carbonato de } \\
\text { cálcio; Óxido de cálcio; Óxido de ferro; Óxido de } \\
\text { zircônio. } \\
\text { Líquido: Cloreto de cálcio; Polímero hidrossolúvel. }\end{array}$ \\
\hline ProRoot $^{\circledR}$ MTA White & $\begin{array}{l}\text { Pó: Cimento Portland; Óxido de bismuto; Sulfato de } \\
\text { cálcio dihidratado; Silicato tricálcico; Silicato dicálcico; } \\
\text { Aluminato tricálcico; Aluminato férrico tetracálcico. } \\
\text { Líquido: Água. }\end{array}$ \\
\hline
\end{tabular}




\section{Processamento histotécnico}

As maxilas e as mandíbulas contendo os dentes foram removidas, dissecadas e seccionadas para obter blocos individuais, contendo os dentes e tecidos perirradiculares adjacentes. Os blocos foram submetidos à fixação em solução de formol tamponado a $10 \%$ por 24 horas e à desmineralização em solução à base de EDTA a 4,13\% (pH 7,4). As peças foram mantidas nesta solução, à temperatura ambiente, trocada semanalmente, até sua completa desmineralização. O grau de desmineralização das estruturas mineralizadas foi testado por meio da penetração de uma agulha nos tecidos, para verificação da sua consistência. Após esse procedimento, as peças foram submetidas ao processamento histotécnico de rotina, sendo lavadas em água corrente por 8 horas, desidratadas em álcool de concentrações crescentes (70\%, $80 \%$ e $95 \%$ por 1 hora cada; 2 trocas de $100 \%$ por 1 hora cada e 1 troca de álcool 100\% overnight), diafanizadas em xilol (3 banhos de 40 minutos) e incluídas em parafina (Histosec Pastillen, Merck).

Os blocos contendo os dentes foram cortados longitudinalmente em micrótomo (Leica RM2145; Leica Microsystems GmbH, Wetzlar, Alemanha), para obtenção de cortes seriados com $5 \mu \mathrm{m}$ de espessura em toda a extensão da furca. Os cortes representativos de cada grupo foram corados com hematoxilina e eosina (HE) para a avalição da formação de tecido mineralizado na região da perfuração e com tricrômico de Masson para avaliação da presença e reinserção de fibras colágenas.

\section{Análise histopatológica}

A análise histopatológica semi-quantitativa do tecido mineralizado neoformado foi realizada na região da perfuração de furca e ligamento periodontal adjacente, na coloração de $\mathrm{HE}$, por meio da atribuição dos seguintes escores: $0=$ ausente; 1 = presente. Na coloração tricrômico de Masson, foi realizada análise qualitativa para descrever a presença de fibras colágenas no ligamento periodontal adjacente à perfuração de furca e a reinserção destas fibras no tecido mineralizado neoformado, quando presente. 
Todas as análises foram realizadas por um único examinador experiente e cego com relação aos grupos, utilizando o microscópio Axio Imager.M1 (Carl Zeiss MicroImaging GmbH, Göttingen, Alemanha), com câmera AxioCam MRc5 acoplada (Carl Zeiss MicroImaging GmbH, Göttingen, Alemanha).

\section{Análise imunohistoquímica}

A análise de imunohistoquímica foi empregada para determinar a intensidade de marcação para a Osteopontina (OPN) e para a Fosfatase Alcalina (ALP), por meio da técnica da imunoperoxidase (Silva et al., 2012).

Os cortes histológicos foram desparafinizados, sendo os epítopos antigênicos recuperados com calor utilizando tampão citrato $(\mathrm{pH}=6,0)$ em forno de micro-ondas. Após retornarem à temperatura ambiente, as lâminas foram lavadas 2 vezes por 5 minutos com PBS e 1 vez com solução PBS/Triton (Sigma-Aldrich Corporation, Saint Louis, EUA) pelo mesmo período. $O$ bloqueio da peroxidase endógena foi realizado com peróxido de hidrogênio a $3 \%$ por 40 minutos. A seguir, as lâminas foram novamente lavadas com PBS e PBS/Triton, conforme descrito anteriormente. $O$ bloqueio das ligações inespecíficas foi realizado com solução de 3\% BSA (albumina de soro bovino)/PBS, por 1 hora. A seguir, as lâminas foram incubadas overnight, em geladeira, com os anticorpos primários diluídos em BSA a 3\%: anti-OPN (rabbit polyclonal antibody, ab8448, Abcam PLC, diluído 1:150) e anti-ALP (mouse monoclonal antibody, sc-271431, Santa Cruz Biotechnology Inc., diluído 1:50).

Após retornarem à temperatura ambiente, as lâminas foram lavadas e incubadas com anticorpo secundário biotinilado (goat anti-mouse IgG-B sc-2039 e goat anti-rabbit IgG-B sc-2040; Santa Cruz Biotechnology Inc., diluídos 1:200), por 1 hora à temperatura ambiente. Depois de nova lavagem, foi colocado o complexo avidina-biotina-peroxidase (ABC kit, Vecstain; Vector Laboratories Inc.) por 30 minutos. A seguir, as lâminas foram novamente lavadas com PBS e PBS/Triton e foi efetuada a revelação da reação com solução de diaminobenzidina (DAB; SigmaAldrich Corporation, Saint Louis, EUA) e $\mathrm{H}_{2} \mathrm{O}_{2}$ a $3 \%$ em PBS, por 1 minuto. As lâminas foram contra-coradas com Hematoxilina de Harris por 10 segundos, lavadas 
em água corrente, lavadas em água amoniacal por 30 segundos, lavadas em água corrente, diafanizadas, desidratadas e montadas.

A análise foi realizada em microscópio Axio Imager.M1 sob luz convencional. A marcação positiva para OPN ou ALP foi avaliada por meio dos escores - ausente (0), suave (1), moderada (2) ou intensa (3), na região do tecido mineralizado formado e no espaço do ligamento periodontal adjacente a este tecido ou à perfuração. Todas as análises foram realizadas por um único examinador experiente e cego com relação aos grupos.

\section{Imunofluorescência}

A marcação com dupla imunofluorescência foi realizada utilizando anticorpos policlonais contra a proteína morfogenética óssea (BMP-2), sialoproteína óssea $(B S P)$, osteocalcina $(\mathrm{OCN})$, proteína do cemento 1 (CEMP1) e anticorpo monoclonal contra a proteína de adesão do cemento (CAP) (Santa Cruz Biotechnology, Inc. EUA). As lâminas foram pré-tratadas com BSA diluído em PBS na concentração de $10 \%$, durante 1 hora, à temperatura ambiente e incubadas com o anticorpo monoclonal primário (diluição de 1:150) e com os anticorpos policlonais (diluição de 1:250) durante 12 horas, a $4^{\circ} \mathrm{C}$. As lâminas foram então incubadas com os anticorpos secundários IgG anti-mouse conjugado com FITC, na diluição de 1:50 (Molecular Probes; Eugene, OR, EUA) e IgG anti-rabbit conjugado com Alexa-Fluor-594, na diluição de 1:400 (Molecular Probes), durante 1 hora, à temperatura ambiente.

As análises foram realizadas utilizando um microscópio fluorescente (Axioskope 2, Carl Zeiss, Alemanha) com as combinações de filtros apropriadas. Os controles negativos foram obtidos por omissão do anticorpo primário. Os resultados foram expressos de acordo com a presença ou ausência de imunomarcação.

Histoenzimologia para a atividade da fosfatase ácida resistente ao tartarato (TRAP), para contagem de osteoclastos

A atividade da TRAP foi utilizada para a marcação de osteoclastos. Os cortes foram desparafinizados e hidratados. A seguir, as lâminas foram colocadas em 
solução de álcool/acetona a $50 \%$ durante um minuto e os cortes secos à temperatura ambiente. Então, uma solução contendo $10 \mathrm{~mL}$ de tampão de ácido acético, 0,1 $\mathrm{mL}$ de dimetilformamida, $5 \mathrm{mg}$ de Fast-red e $1 \mathrm{mg}$ de ácido fosfórico naftol AS-BI (Sigma-Aldrich Corporation, Saint Louis, EUA) foi pipetada sobre os cortes, que foram mantidos protegidos da luz, em estufa a $37^{\circ} \mathrm{C}$, pelo tempo suficiente para se observar a marcação (Cohenca et al., 2015). Após a incubação, foi realizada a contra-coloração com hematoxilina, por um minuto. A seguir, as lâminas foram montadas e avaliadas no microscópio Axio Imager.M1 sob luz convencional, para contagem do número de células TRAP-positivas, com três ou mais núcleos, presentes no espaço do ligamento periodontal adjacente à perfuração ou ao tecido mineralizado neoformado. Os resultados foram expressos em número de células.

\section{Análise estatística}

Os dados obtidos foram submetidos à análise estatística, por meio do programa Graph Pad Prism 4.0 (Graph Pad Software Inc, San Diego, CA, EUA). Os resultados obtidos após as avaliações histopatológicas e imunohistoquímicas foram transformados em porcentagem e analisados pelo teste qui-quadrado. Com relação à avaliação dos osteoclastos, foi utilizado o teste Kruskal-Wallis. O nível de significância adotado para todas as análises foi de $5 \%$. 

Resultados 



\section{RESULTADOS}

\section{Análise histopatológica}

Com relação à análise do tecido mineralizado neoformado (HE - Figura 1), o grupo tratado com guta-percha (controle) foi significantemente diferente dos demais grupos $(p<0,0001)$, não sendo observado selamento da perfuração de furca com tecido mineralizado em nenhum espécime desse grupo. Com relação aos grupos tratados com MTA e Biodentine, ambos os grupos induziram o reparo, por meio da formação de tecido mineralizado na região da perfuração. Foi observado o selamento da perfuração de furca em $88 \%$ dos espécimes tratados com MTA e em $92 \%$ dos espécimes tratados com Biodentine, sem diferença estatisticamente significante entre estes grupos $(p>0,05)$.

Com relação à análise qualitativa das fibras colágenas (tricrômico de Masson - Figura 2), o grupo tratado com guta-percha apresentou fibras colágenas na região do ligamento periodontal adjacente à perfuração. Entretanto, essas fibras eram esparsas e encontravam-se paralelas à região da perfuração. Nos grupos tratados com MTA ou Biodentine, também foi possível observar presença fibras colágenas paralelas à região da perfuração. Entretanto, diferentemente do observado no grupo controle, em todos os casos tratados com MTA ou Biodentine houve uma presença suave de fibras reinseridas perpendicularmente em diferentes áreas do tecido mineralizado neoformado, quando presente. Essa reinserção foi parcial, não ocorrendo em toda a região do ligamento periodontal adjacente à perfuração. 



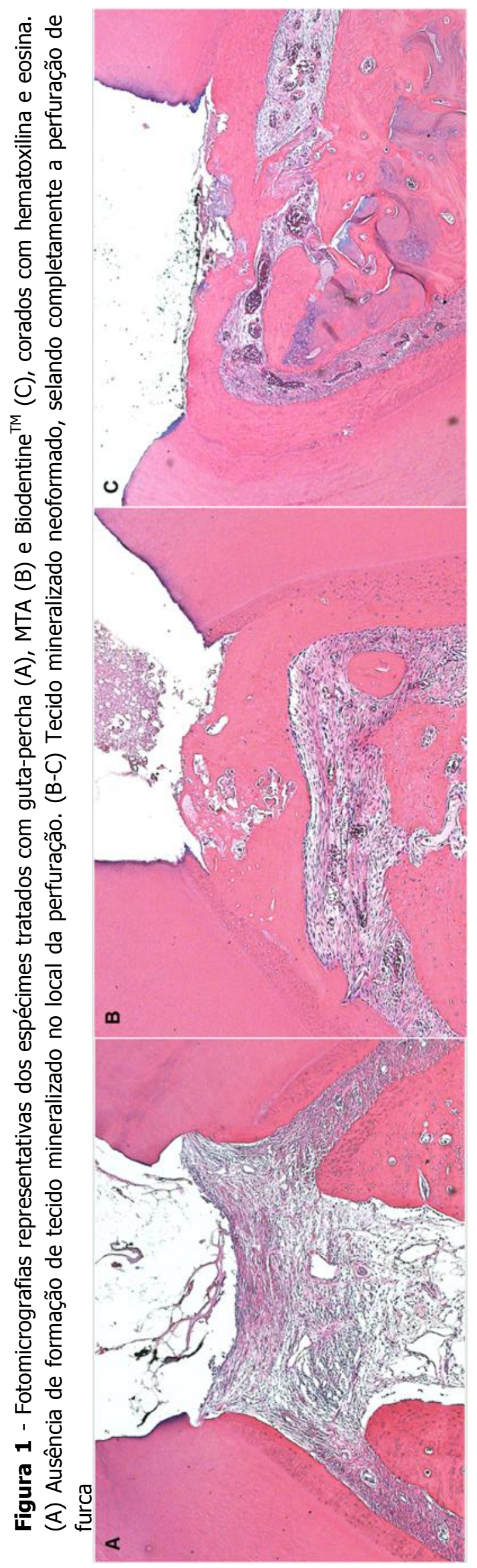



Figura 2 - Fotomicrografias representativas dos espécimes tratados com guta-percha (A-B), MTA (CD) e Biodentine ${ }^{T M}(E-F)$, corados com tricrômico de Masson. (A-B) Fibras colágenas esparsas e paralelas na região do ligamento periodontal adjacente à perfuração. (C-D-E-F) Presença de fibras reinseridas perpendicularmente em diferentes áreas do tecido mineralizado neoformado
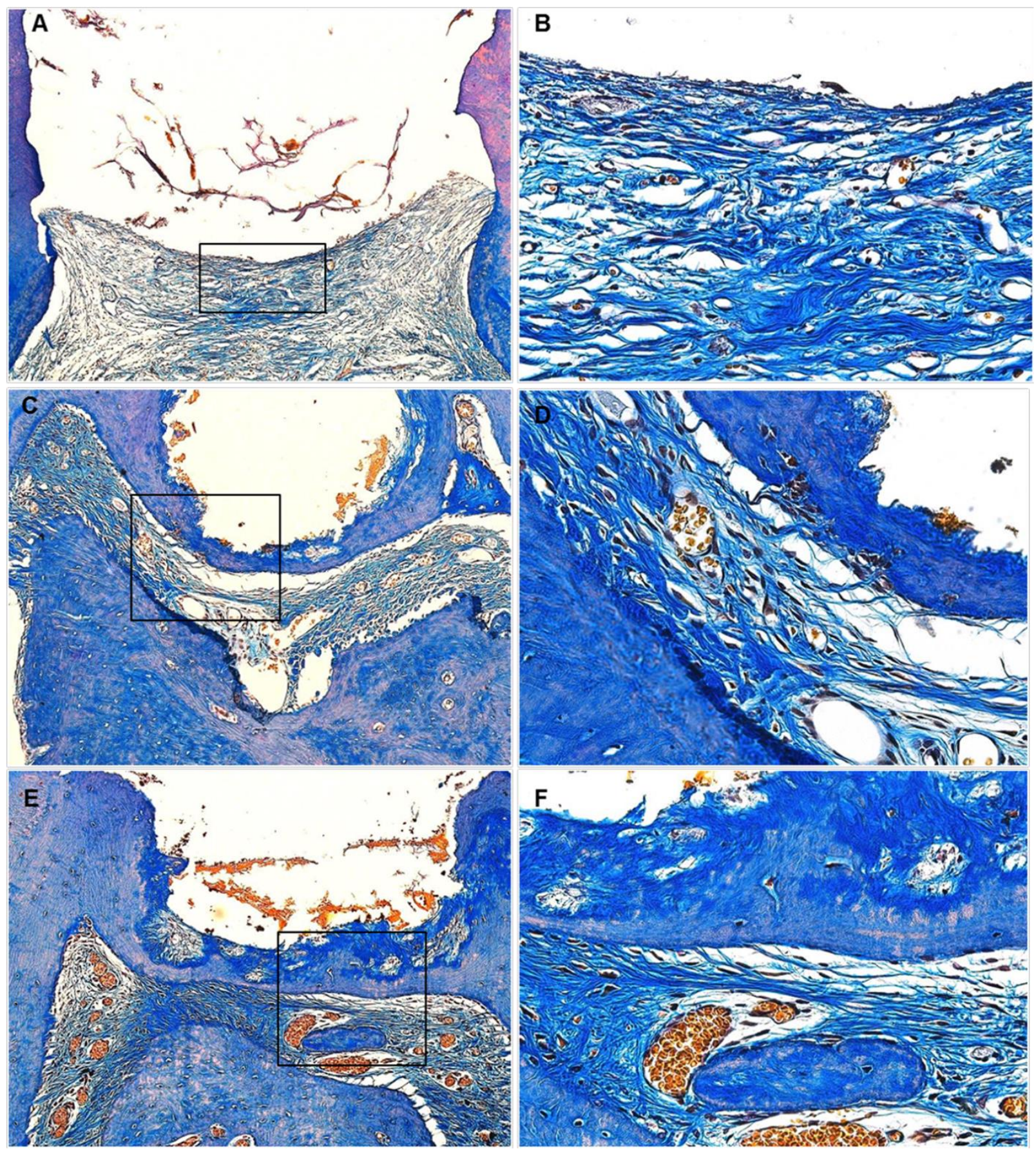



\section{Análise imunohistoquímica}

A análise estatística após a avaliação das imunomarcações para OPN revelou que no grupo controle (guta-percha) houve marcação significantemente mais suave $(p<0,0001)$, em comparação à Biodentine e ao MTA, os quais também foram diferentes entre si $(p<0,001)$, com marcação mais intensa para o MTA. Em porcentagem e considerando a intensidade da marcação positiva para OPN como suave, moderada e intensa, foram obtidos os seguintes resultados, respectivamente: $50 \%, 17 \%$ e $33 \%$ para o grupo controle; $30 \%$, $70 \%$ e $0 \%$ para a Biodentine; $25 \%$, $50 \%$ e $25 \%$ para o MTA (Figura 3).

Com relação à marcação para ALP, o mesmo padrão foi observado, com marcação mais intensa no grupo tratado com MTA $(p<0,0001)$. Expressando esses resultados em porcentagem e considerando a intensidade da marcação positiva para ALP como suave, moderada e intensa, foram obtidos os seguintes resultados, respectivamente: $33 \%$, 67\% e $0 \%$ para o grupo controle; $18 \%$, 64\% e $18 \%$ para a Biodentine; 0\%, 50\% e 50\% para o MTA (Figura 4).

Resumidamente, pode-se dizer que todos os tratamentos induziram a expressão de OPN e ALP, porém em menor intensidade no grupo tratado com a guta-percha e em maior intensidade no grupo tratado com MTA.

\section{Imunofluorescência}

Os resultados desta avaliação indicaram que apenas as perfurações de furca tratadas com MTA promoveram a formação de um tecido mineralizado com características semelhantes ao cemento. Como observado pela dupla imunofluorescência (Figura 5), os anticorpos testados (BMP-2, CAP, BSP, OCN e CEMP1) reagiram com células semelhantes a cementoblastos. 
Histoenzimologia para a atividade da fosfatase ácida resistente ao tartarato (TRAP)

No grupo controle a mediana foi de 2 osteoclastos (Q1=0; $Q 3=5)$, no grupo tratado com Biodentine foi de $2(\mathrm{Q} 1=0,75 ; \mathrm{Q} 3=4)$ e no grupo tratado com MTA foi de 3 osteoclastos $(\mathrm{Q} 1=0 ; \mathrm{Q} 3=3)$. Não foi possível encontrar diferença estatística entre os grupos $(p=0,97)$. A Figura 6 ilustra os resultados obtidos. 
Figura 3 - Fotomicrografias representativas dos espécimes tratados com guta-percha (A-B), MTA (CD) e Biodentine ${ }^{T M}(E-F)$, com relação à imunomarcação para osteopontina (OPN). Imunomarcação (marrom) leve nos espécimes tratados com guta-percha e moderada nos espécimes tratados com MTA ou Biodentine

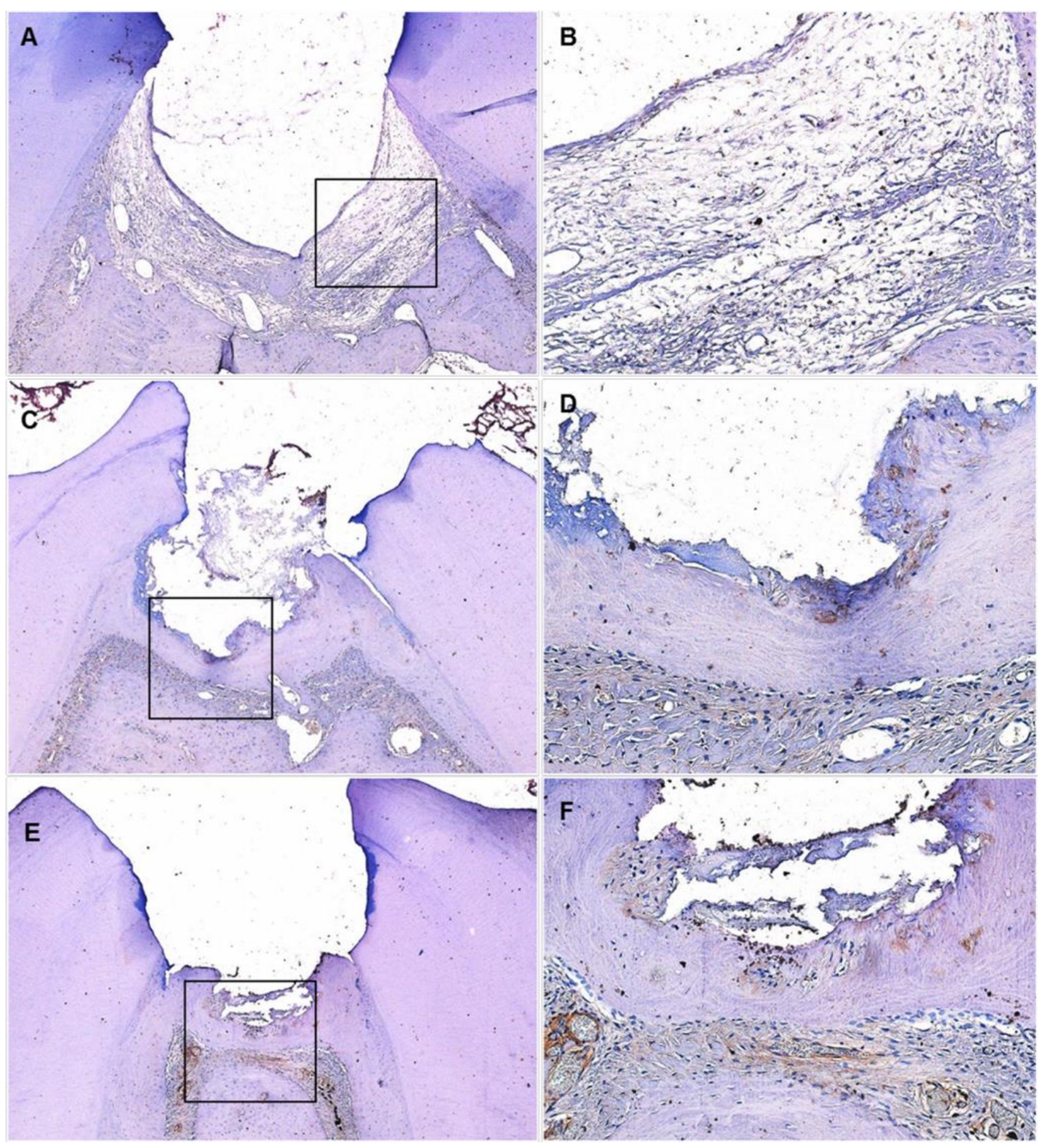



Figura 4 - Fotomicrografias representativas dos espécimes tratados com guta-percha (A-B), MTA (C$D)$ e Biodentine ${ }^{T M}(E-F)$, com relação à imunomarcação para fosfatase alcalina (ALP). Imunomarcação (marrom) leve nos espécimes tratados com guta-percha, moderada nos espécimes tratados com Biodentine e intensa nos espécimes tratados com MTA

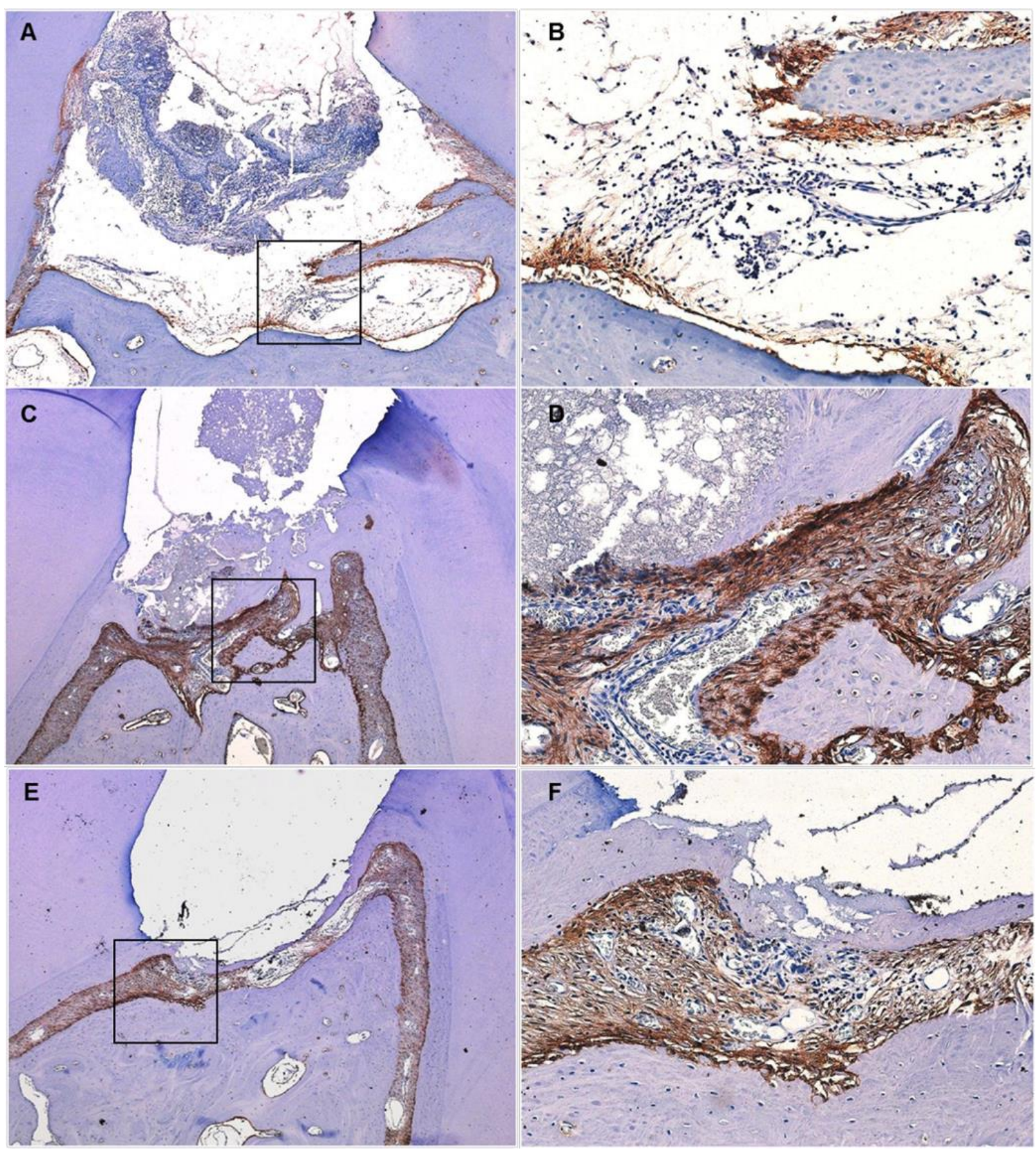



Figura 5 - Fotomicrografias representativas (A-T) dos espécimes tratados com MTA. Imunofluorescência para proteína morfogenética óssea (BMP-2), proteína de adesão do cemento $(\mathrm{CAP})$, sialoproteína óssea (BSP), osteocalcina (OCN) e proteína do cemento 1 (CEMP1). A-C: BSP e BMP2 foram fortemente expressas por células semelhantes aos cementoblastos. Ambos os marcadores de cemento CAP (E-G) e CEMP1 (I-K) também reagiram de forma cruzada com células semelhantes aos cementoblastos (CB), cementócitos (CT) e células do ligamento periodontal. M-O: OCN foi expressa por cementoblastos e também estava presente na matriz extracelular do cemento. Q-S: Controles negativos (-C). D,H,L,P,: Orientação anatômica na coloração tricrômica de Masson (TM)

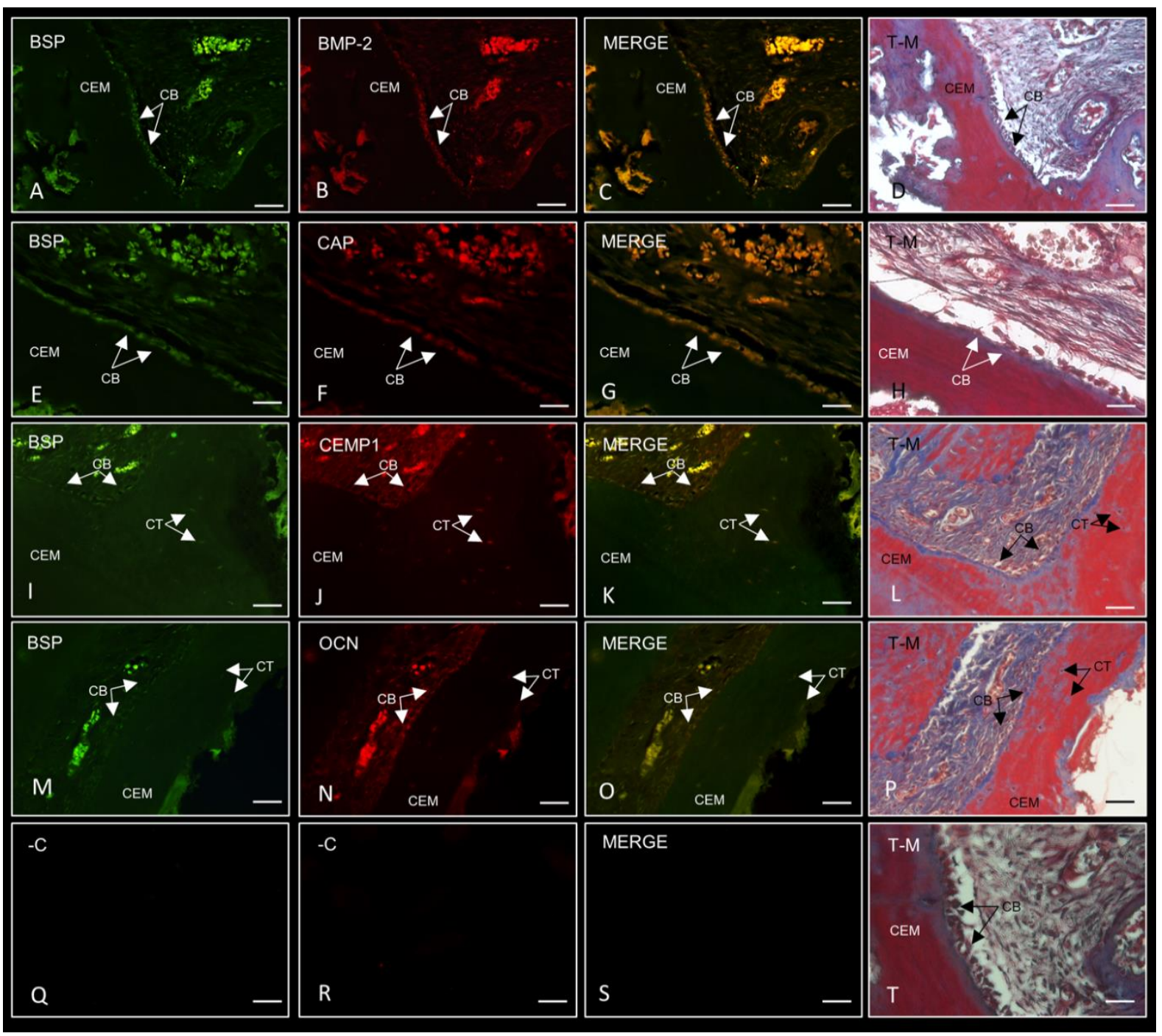



Figura 6 - Fotomicrografias representativas dos espécimes tratados com guta-percha (A-B), MTA (CD) e Biodentine ${ }^{T M}(E-F)$, corados por meio da técnica de histoenzimologia para a atividade da fosfatase ácida resistente ao tartarato (TRAP), para identificação e contagem de células osteoclásticas (setas)

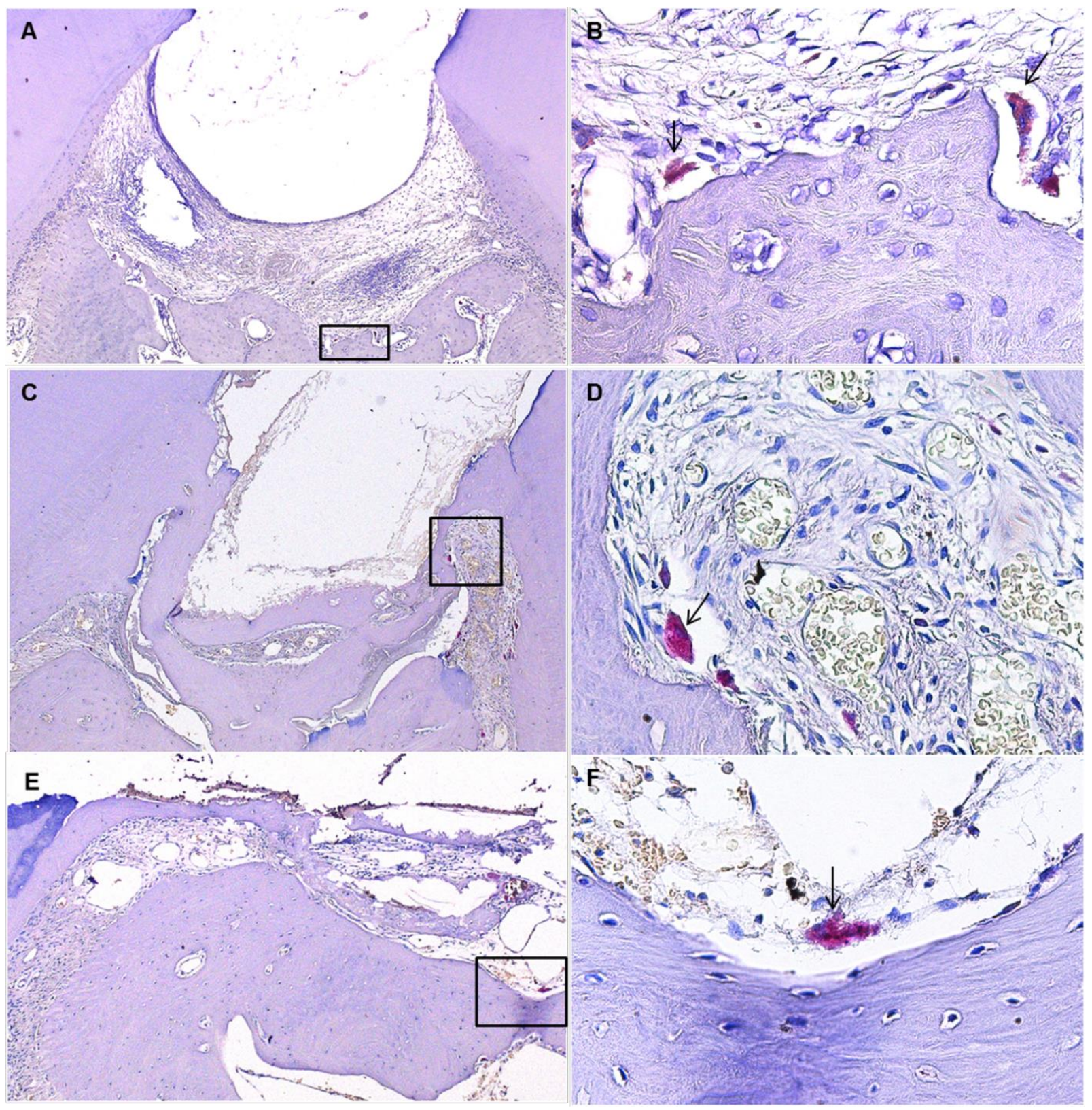



$D_{\text {iscussão }}$ 



\section{DisCUSSÃO}

A formação de tecido mineralizado após a aplicação de materiais seladores em perfurações de furca é um fator importante e considerado como o resultado final ideal de um tratamento (Zairi et al., 2012). Após análise histopatológica, o presente estudo demonstrou que as perfurações tratadas com MTA e Biodentine apresentaram alta frequência de formação de tecido mineralizado, promovendo o reparo das lesões. Nossos resultados concordam com estudos prévios que também observaram altas frequências de formação de tecido mineralizado, após tratamento de perfurações de furca com MTA, em dentes de cães (Samiee et al., 2010; Zairi et al., 2012; Silva et al., 2017).

Até o momento, apenas um estudo publicado por Silva et al., em 2017, avaliou o efeito biológico da Biodentine após aplicação em perfurações de furca, in vivo. Estes autores, assim como o presente estudo, evidenciaram que este material apresentou bons resultados histopatológicos, induzindo o reparo parcial ou total da perfuração de furca, em quase todos os casos. Além disso, já foi demonstrado que a Biodentine e o MTA induziram a formação de tecido mineralizado no terço cervical da polpa do canal radicular, após a realização de pulpotomia e capeamento pulpar com esses materiais (Daltoe et al., 2016). Entretanto, o presente estudo foi o primeiro a elucidar algumas particularidades do mecanismo de ação que provoca a mineralização, após o uso desses materiais em perfurações de furca, avaliando marcadores da formação óssea e de cemento por meio de imunohistoquímica e imunofluorescência.

Sabe-se que a Biodentine e o MTA induzem a proliferação celular, aumentam a atividade da fosfatase alcalina, a formação de nódulos mineralizados e a expressão de genes marcadores de odontoblastos, em células da polpa dentária humana (Chang et al., 2014). Entretanto, o presente estudo foi o primeiro a avaliar marcadores da mineralização (ALP e OPN), após o uso de MTA ou Biodentine em perfurações de furca, demonstrando que ambos os materiais induziram uma maior expressão de ALP e OPN, em comparação ao grupo controle, com marcação mais intensa no grupo tratado com MTA. A ALP e a OPN são frequentemente utilizadas 
como marcadores da diferenciação osteoblástica no intuito de se avaliar os mecanismos envolvidos no processo de mineralização (Goldberg et al., 1995; Chang et al., 2014). A primeira está relacionada com a fase inicial do processo de mineralização (Schouten et al., 2009), enquanto a segunda tem sido relacionada com a manutenção da integridade tecidual durante os processos inflamatórios (Denhardt et al., 2001).

No presente estudo, foi observada uma marcação intensa de ALP, concordando estudos prévios que sugeriram que a ALP desempenha uma função importante na reação inicial do organismo à injúria tecidual. Estudos in vitro (Peng et al., 2011; Wang et al., 2014; Daltoe et al., 2016) observaram um aumento na expressão da ALP após estimulação com MTA e Biodentine em células da polpa dentária de dentes permanentes humanos. Um estudo in vivo (Daltoe et al., 2016) observou um aumento na expressão de ALP no tecido mineralizado formado após pulpotomia e capeamento pulpar com Biodentine e MTA, em dentes de cães.

Estudos prévios mostraram um aumento da expressão de OPN in vitro após a estimulação com Biodentine e MTA, sem diferença entre os materiais, em células da polpa dentária (Chang et al., 2014; Daltoe et al., 2016). Intensa marcação para OPN também foi demonstrada, in vivo, após capeamento pulpar com MTA e Biodentine em dentes de roedores (Tran et al., 2012). Resultados semelhantes foram observados por Daltoé et al. (2016), com marcação mais intensa nos dentes tratados com Biodentine, em dentes de cães. O presente estudo é o único que investigou a expressão dos marcadores da mineralização ALP e OPN após tratamento de perfurações de furca com MTA e Biodentine, in vivo, o que impossibilita uma comparação direta com estudos prévios.

O MTA é considerado um material biocompatível e estimula o reparo dos tecidos perirradiculares. Entretanto, a natureza do tecido mineralizado neoformado, assim como o mecanismo que controla a formação deste tecido, necessitam ser melhor elucidados. O presente estudo demonstrou a expressão de OCN, BMP-2 e BSP no tecido mineralizado neoformado, após o tratamento das perfurações de furca com MTA. A OCN é uma proteína óssea não-colágena e desempenha um papel regulador na mineralização do tecido mineralizado. Em contato com o MTA há produção de OCN por células osteoblásticas in vitro (Tani-Ishii et al., 2007). Além 
disso, o MTA induz a expressão dos marcadores osteogênicos BMP-2 e OCN, em células da polpa dentária (Rodrigues et al., 2017a) e ambos os materiais, MTA e Biodentine, induzem a expressão de BMP-2 em células osteogênicas e são considerados materiais adequados para estimular a mineralização por células osteoblásticas (Rodrigues et al., 2017b). A BSP também participa do processo de formação da matriz mineralizada e a expressão desta proteína é altamente específica para tecidos mineralizados, incluindo osso, cartilagem, dentina e cemento (Tani-Ishii et al., 2007). Estudo prévio demonstrou que células da polpa dentária tratadas com MTA aumentaram significantemente a expressão do mRNA de marcadores da diferenciação odontoblástica, tais como BSP e OCN (Zhao et al., 2012).

O presente estudo demonstrou a expressão de marcadores da cementogênese (CAP e CEMP-1) apenas no tecido mineralizado neoformado após o uso do MTA em perfurações de furca, sugerindo que este material promoveu a formação de um tecido mineralizado com características semelhantes ao cemento. Sabe-se que o MTA tem a capacidade de induzir a proliferação de cementoblastos e pode ser considerado como indutor da cementogênese (Hakki et al., 2009). Por outro lado, a Biodentine induz a formação de focos de mineralização logo após a sua aplicação e essa mineralização parece acontecer na forma de osteodentina, expressando marcadores de odontoblastos (Laurent et al., 2012). O presente estudo foi o primeiro a investigar a expressão desses marcadores no tecido mineralizado neoformado após o uso de MTA e Biodentine em perfurações de furca, in vivo, impossibilitando uma comparação direta com estudos prévios.

Além disso, o presente estudo avaliou a reinserção de fibras colágenas após o uso dos cimentos à base de silicato de cálcio, demonstrando que, no período avaliado, esses materiais não promoveram a reinserção de fibras do ligamento periodontal no tecido mineralizado neoformado em sua totalidade, havendo apenas uma reinserção parcial. $O$ efeito do MTA em células indiferenciadas mesenquimais durante o reparo do ligamento periodontal e dos tecidos perirradiculares circundantes foi estudado por Vidovic Zdrilic et al. (2017), que observaram que o selamento da perfuração de furca com MTA melhorou significativamente o processo de reparo. O MTA promoveu a regeneração do ligamento periodontal e do osso alveolar lesionados em dentes de roedores. Entretanto, apesar dos progressos 
realizados na compreensão dos efeitos biológicos do MTA, seu mecanismo de ação que leva ao reparo tecidual e a natureza da formação do tecido mineralizado formado permanecem pouco esclarecidos (Vidovic Zdrilic et al., 2017). Além disso, a falta de estudos avaliando a resposta tecidual perirradicular, após o uso da Biodentine em perfurações de furca, englobando os aspectos avaliados no presente estudo, impossibilita a comparação dos nossos resultados com estudos prévios.

Em estudo recente (Gandolfi et al., 2017), os cimentos silicato de cálcio (Biodentine, MTA Plus e ProRoot MTA) foram avaliados in vivo para testar o potencial de reparo ósseo e propriedades de mineralização em defeitos ósseos intramedulares em coelhos, mostrando o efeito osteogênico desses cimentos, que promoveram uma neoformação óssea com processos ativos de biomineralização ao redor dos materiais. Análises histopatológicas mostraram que todos os materiais testados induziram neoformação óssea intramedular, diferenciação osteoblástica e angiogênese, demonstrando compatibilidade tecidual. Esses autores observaram que o ProRoot MTA e o MTA Plus apresentaram potencial bioativo, pois se uniram ao osso diretamente, sem tecido conjuntivo interposto. Já a Biodentine foi substituída por osso recém-formado. Além disso, não foram evidenciados osteoclastos e nenhuma formação de tecido fibroso.

O presente estudo também foi o primeiro a avaliar a presença de osteoclastos no tecido mineralizado neoformado e na região adjacente, após o tratamento de perfurações de furca com MTA e Biodentine, in vivo. Em geral, foi encontrada uma pequena quantidade dessas células, sem diferença entre os grupos. Sabe-se que a atividade alcalinizante dos materiais pode ter efeito no recrutamento e na ativação de osteoclastos, inativando essas células (Arnett, 2008; Hashiguchi et al., 2011). Estudos prévios demonstraram uma forte atividade alcalinizante no MTA, sendo menor para a Biodentine (Prati e Gandolfi, 2015).

Sumarizando, o presente estudo demonstrou que o MTA e a Biodentine, em contato com os tecidos perirradiculares, induziram o reparo das perfurações de furca com formação de tecido mineralizado e reinserção parcial de fibras. Ambos os materiais induziram a expressão dos marcadores da mineralização ALP e OPN, com maior intensidade para o MTA, e apenas este material estimulou a expressão de 
proteínas associadas à formação de tecido mineralizado semelhante ao cemento. Além disso, ambos os materiais não interferiram na quantidade de osteoclastos.

Estudos adicionais in vivo são necessários com a finalidade de elucidar outros possíveis mecanismos de ação que levam à indução da mineralização, após o selamento de perfurações de furca com MTA ou Biodentine. 

Conclusão 

CONCLUSÃO

Com base nos parâmetros analisados, pôde-se concluir que o MTA e a Biodentine apresentaram resposta tecidual satisfatória, com formação de tecido mineralizado e reinserção parcial de fibras, podendo ser indicados para o selamento de perfurações de furca. Além disso, o presente estudo elucidou alguns mecanismos de ação pelo quais o MTA e a Biodentine induzem a formação do tecido mineralizado, com expressão dos marcadores da mineralização ALP e OPN, sem interferência na quantidade de osteoclastos. Apenas o MTA estimulou a expressão de proteínas associadas à formação de tecido mineralizado semelhante ao cemento. 

Referências 



\section{REFERÊNCIAS}

1. Aggarwal V, Singla M, Miglani S, Kohli S. Comparative evaluation of push-out bond strength of ProRoot MTA, Biodentine, and MTA Plus in furcation perforation repair. J Conserv Dent. 2013;16(5):462-5.

2. American Association of Endodontists. American Association of Endodontists Glossary of Endodontic Terms, 9th ed. Chicago, IL: American Association of Endodontists; 2015.

3. Arnett TR. Extracellular $\mathrm{pH}$ regulates bone cell function. J Nutr. 2008;138(2):415s-8s.

4. Bakhtiar $\mathrm{H}$, Mirzaei $\mathrm{H}$, Bagheri MR, Fani N, Mashhadiabbas F, Baghaban Eslaminejad $M$, et al. Histologic tissue response to furcation perforation repair using mineral trioxide aggregate or dental pulp stem cells loaded onto treated dentin matrix or tricalcium phosphate. Clin Oral Investig. 2017;21(5):1579-88.

5. Camilleri J. Characterization of hydration products of mineral trioxide aggregate. Int Endod J. 2008;41(5):408-17.

6. Camilleri J. Investigation of Biodentine as dentine replacement material. J Dent. 2013;41(7):600-10.

7. Cardoso M, Catre D, Noites R, Paulo M, Viegas C. Animal models used in furcation perforation studies: A systematic review and comprehensive synthesis of model characteristics. Aust Endod J. 2017.

8. Chang SW, Lee SY, Ann HJ, Kum KY, Kim EC. Effects of calcium silicate endodontic cements on biocompatibility and mineralization-inducing potentials in human dental pulp cells. J Endod. 2014;40(8):1194-200.

9. Cheng X, Zhu L, Zhang J, Yu J, Liu S, Lv F, et al. Anti-osteoclastogenesis of Mineral Trioxide Aggregate through Inhibition of the Autophagic Pathway. J Endod. 2017;43(5):766-73.

10. Cohenca N, Romualdo PC, da Silva LA, da Silva RA, de Queiroz AM, De Rossi A, Nelson-Filho $P$. Tissue response to root canal irrigation systems in dogs' teeth with apical periodontitis. Clin Oral Investig. 2015;19(5):1147-56.

11. Daltoe MO, Paula-Silva FW, Faccioli LH, Gaton-Hernandez PM, De Rossi A, Bezerra Silva LA. Expression of Mineralization Markers during Pulp Response to Biodentine and Mineral Trioxide Aggregate. J Endod. 2016;42(4):596-603.

12. De Rossi A, Silva LA, Gaton-Hernandez $P$, Sousa-Neto MD, Nelson-Filho $P$, Silva RA, De Queiroz AM. Comparison of pulpal responses to pulpotomy and pulp capping with biodentine and mineral trioxide aggregate in dogs. J Endod. 2014;40(9):1362-9.

13. Denhardt DT, Noda M, O'Regan AW, Pavlin D, Berman JS. Osteopontin as a means to cope with environmental insults: regulation of inflammation, tissue remodeling, and cell survival. J Clin Invest. 2001;107(9):1055-61. 
14. Flores-Ledesma A, Barceló Santana F, Bucio L, Arenas-Alatorre JA, Faraji M, Wintergerst AM. Bioactive materials improve some physical properties of a MTA-like cement. Mater Sci Eng C Mater Biol Appl. 2017;71:150-155.

15. Gandolfi MG, Iezzi G, Piattelli A, Prati C, Scarano A. Osteoinductive potential and bone-bonding ability of ProRoot MTA, MTA Plus and Biodentine in rabbit intramedullary model: Microchemical characterization and histological analysis. Dent Mater. 2017;33(5):e221-e38.

16. Gilles R, Olivier M. Dental composition. Patent 2011, WO 2011/124841, US 2013/0025498. Applicant Septodont, Saint- Maur-des-Fossés, France.

17. Goldberg M, Septier D, Lecolle S, Chardin H, Quintana MA, Acevedo AC, et al. Dental mineralization. Int J Dev Biol. 1995;39(1):93-110.

18. Hakki SS, Bozkurt SB, Hakki EE, Belli S. Effects of mineral trioxide aggregate on cell survival, gene expression associated with mineralized tissues, and biomineralization of cementoblasts. J Endod. 2009;35(4):513-9.

19. Hashiguchi D, Fukushima H, Yasuda H, Masuda W, Tomikawa M, Morikawa $\mathrm{K}$, Maki K, Jimi E. Mineral trioxide aggregate inhibits osteoclastic bone resorption. J Dent Res. 2011;90(7):912-7.

20. Katge FA, Shivasharan PR, Patil D. Sealing ability of mineral trioxide aggregate Plus ${ }^{\mathrm{TM}}$ and Biodentine ${ }^{\mathrm{TM}}$ for repair of furcal perforation in primary molars: An in vitro study. Contemp Clin Dent. 2016;7(4):487-92.

21. Laurent $\mathrm{P}$, Camps J, About I. Biodentine ${ }^{\mathrm{TM}}$ induces TGF-beta1 release from human pulp cells and early dental pulp mineralization. Int Endod $\mathrm{J}$. 2012;45(5):439-48.

22. Leiendecker AP, Qi YP, Sawyer AN, Niu LN, Agee KA, Loushine RJ, Weller RN, Pashley DH, Tay FR. Effects of calcium silicate-based materials on collagen matrix integrity of mineralized dentin. J Endod. 2012;38(6):829-33.

23. Marconyak LJ, Jr., Kirkpatrick TC, Roberts HW, Roberts MD, Aparicio A, Himel VT, Sabey KA. A comparison of coronal tooth discoloration elicited by various endodontic reparative materials. J Endod. 2016;42(3):470-3.

24. Możyńska J, Metlerski M, Lipski M, Nowicka A. Tooth discoloration induced by different calcium silicate-based cements: A systematic review of in vitro studies. J Endod. 2017;43(10):1593-1601.

25. Parirokh $M$, Torabinejad $M$. Mineral trioxide aggregate: a comprehensive literature review--Part III: Clinical applications, drawbacks, and mechanism of action. J Endod. 2010;36(3):400-13.

26. Peng W, Liu W, Zhai W, Jiang L, Li L, Chang J, Zhu Y. Effect of tricalcium silicate on the proliferation and odontogenic differentiation of human dental pulp cells. J Endod. 2011;37(9):1240-6.

27. Prati C, Gandolfi MG. Calcium silicate bioactive cements: Biological perspectives and clinical applications. Dent Mater. 2015;31(4):351-70.

28. Rathinam E, Rajasekharan S, Chitturi RT, Declercq H, Martens L, De Coster P. Gene Expression Profiling and Molecular Signaling of Various Cells in 
Response to Tricalcium Silicate Cements: A Systematic Review. J Endod. 2016;42(12):1713-25.

29. Rodrigues EM, Cornelio ALG, Mestieri LB, Fuentes ASC, Salles LP, RossaJunior C, Faria G, Guerreiro-Tanomaru JM, Tanomaru-Filho M. Human dental pulp cells response to mineral trioxide aggregate (MTA) and MTA Plus: cytotoxicity and gene expression analysis. Int Endod J. 2017;50(8):780-9.

30. Rodrigues EM, Gomes-Cornelio AL, Soares-Costa A, Salles LP, Velayutham M, Rossa-Junior C, Guerreiro-Tanomaru JM, Tanomaru-Filho M. An assessment of the overexpression of BMP-2 in transfected human osteoblast cells stimulated by mineral trioxide aggregate and Biodentine. Int Endod $\mathrm{J}$. 2017;50 Suppl 2:e9-e18.

31. Samiee M, Eghbal MJ, Parirokh M, Abbas FM, Asgary S. Repair of furcal perforation using a new endodontic cement. Clin Oral Investig. 2010;14(6):653-8.

32. Schouten C, van den Beucken JJ, de Jonge LT, Bronkhorst EM, Meijer GJ, Spauwen $\mathrm{PH}$, et al. The effect of alkaline phosphatase coated onto titanium alloys on bone responses in rats. Biomaterials. 2009;30(32):6407-17.

33. Silva LAB, Pieroni $K$, Nelson-Filho $P$, Silva RAB, Hernandez-Gaton $P$, Lucisano MP, Paula-Silva FWG, de Queiroz AM. Furcation perforation: periradicular tissue response to Biodentine as a repair material by histopathologic and indirect immunofluorescence analyses. J Endod. 2017;43(7):1137-42.

34. Silva RA, Ferreira PD, De Rossi A, Nelson-Filho P, Silva LA. Toll-like receptor 2 knockout mice showed increased periapical lesion size and osteoclast number. J Endod. 2012 Jun;38(6):803-13.

35. Singh $P$, Paul J, Al-Khuraif AA, Vellappally S, Halawany HS, Hashim M, Abraham NB, Jacob V, Thavarajah R. Sealing ability of mineral trioxide aggregate, calcium phosphate cement, and glass ionomer cement in the repair of furcation perforations. Acta Medica (Hradec Kralove). 2013;56(3):97-103.

36. Tani-Ishii N, Hamada N, Watanabe K, Tujimoto $\mathrm{Y}$, Teranaka T, Umemoto T. Expression of bone extracellular matrix proteins on osteoblast cells in the presence of mineral trioxide. J Endod. 2007;33(7):836-9.

37. Torabinejad M, Parirokh M, Dummer PMH. Mineral trioxide aggregate and other bioactive endodontic cements: an updated overview - part II: other clinical applications and complications. Int Endod J. 2018 Mar;51(3):284-317.

38. Torabinejad M, Parirokh M. Mineral trioxide aggregate: a comprehensive literature review--part II: leakage and biocompatibility investigations. J Endod. 2010;36(2):190-202.

39. Tran XV, Gorin C, Willig C, Baroukh B, Pellat B, Decup F, et al. Effect of a calcium-silicate-based restorative cement on pulp repair. J Dent Res. 2012;91(12):1166-71. 
40. Unal GC, Maden M, Isidan T. Repair of furcal iatrogenic perforation with mineral trioxide aggregate: two years follow-up of two cases. Eur J Dent. 2010;4(4):475-81.

41. Vidovic Zdrilic I, de Azevedo Queiroz IO, Matthews BG, Gomes-Filho JE, Mina $M$, Kalajzic I. Mineral trioxide aggregate improves healing response of periodontal tissue to injury in mice. J Periodontal Res. 2017;52(6):1058-67.

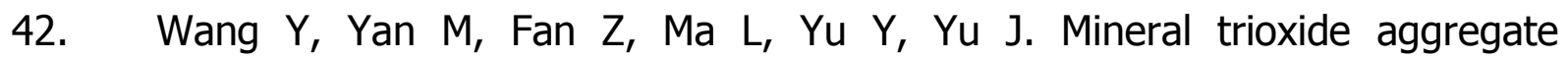
enhances the odonto/osteogenic capacity of stem cells from inflammatory dental pulps via NF-kappaB pathway. Oral Dis. 2014;20(7):650-8.

43. Zairi $A$, Lambrianidis $T$, Pantelidou $O$, Papadimitriou $S$, Tziafas $D$. Periradicular tissue responses to biologically active molecules or MTA when applied in furcal perforation of dogs' teeth. Int J Dent. 2012;2012:257832.

44. Zhao X, He W, Song Z, Tong Z, Li S, Ni L. Mineral trioxide aggregate promotes odontoblastic differentiation via mitogen-activated protein kinase pathway in human dental pulp stem cells. Mol Biol Rep. 2012;39(1):215-20.

45. Zhou HM, Shen Y, Wang ZJ, Li L, Zheng YF, Hakkinen L, Haapasalo M. In vitro cytotoxicity evaluation of a novel root repair material. J Endod. 2013;39(4):478-8. 